\title{
The displays of the White-throated Manakin Corapipo gutturalis in Suriname
}

\author{
RICHARD OWEN PRUM \\ Museum of Zoology, Department of Ecology and Evolutionary Biology, The University \\ of Michigan, Ann Arbor, MI 48109 , USA
}

Accepted 15 April 1985

\begin{abstract}
The courtship displays of the White-throated Manakin Corapipo gutturalis (Pipridae) were observed in the Brownsberg Nature Preserve, Suriname, for over $50 \mathrm{~h}$ on 17 days between 17 October and 17 December 1982, and the display elements and calls are described. Males perform displays from perches in trees, in flight and on mossy fallen logs. The perch displays are performed as preliminaries to the logapproach displays which are given while in flight towards the log. The log-approach displays vary in length and complexity from a short flight from a nearby perch down to the log, to a dramatic flight above the canopy and back to the log. As males land, they perform a series of aerial manoeuvres and give a complex vocal and mechanical display call. Males may also perform a slower silent moth-flight log approach. The log displays are the culminating elements of courtship and copulation is known to take place there (Davis, T.A.W. 1949. Ibis 91: 146-147). All the courtship displays can be performed either solitarily by a single male or by a group of up to seven males which compete simultaneously for access to single display sites at a series of different logs. Fourteen display logs were located dispersed in two areas $250 \mathrm{~m}$ wide which were separated by $350 \mathrm{~m}$, but it was not determined whether these areas constituted separate leks with different pools of possible mates. The behaviour of $C$.gutturalis is compared with that of the White-ruffed Manakin Corapipo leucorrhoa and other manakins. Male Corapipo appeat to have abandoned defence of exclusive advertisement territories in favour of simultaneous competition for a series of different display sites. This detached or mobile form of lek is unique among known manakins and a mechanism for its evolution through female choice is discussed.
\end{abstract}

The White-throated Manakin Corapipo gutturalis is found in the forest of southeastern Venezuela, the Guianas and adjacent northern Brazil from 200 to 1100 m (Meyer de Schauensee 1970, Meyer de Schauensee \& Phelps 1978). While the courtship displays of many manakin species have been well documented, the behaviour of $C$.gutturalis is known from only two short observations. T. A. W. Davis (1949) briefly observed a group of six or more males and females chasing each other around the forest near Mazaruni Station, Guyana. He also observed a male displaying and a pair copulating on a mossy fallen log. T. H. Davis (1982) observed a single male which performed repeated 'flight-song' displays above the canopy in Suriname. These two vastly different reports imply that the courtship display of $C$. gutturalis is complex, highly varied and among the most striking of any manakin species.

From October to December 1982, I observed the courtship behaviour of $C$. gutturalis at the Brownsberg Nature Preserve in central Suriname. In this paper I describe the elements and composition of the display and present evidence of the spatial and social organization of the display groups. I then compare these behaviours with those of other known manakins and briefly discuss the evolution of the breeding system of Corapipo. 


\section{Study area and methods}

The Brownsberg Nature Preserve is located at $4^{\circ} 53^{\prime} \mathrm{N}, 55^{\circ} 13^{\prime} \mathrm{W}$ in the district of Brokopondo, Suriname. The preserve is operated by the Suriname Foundation for Nature Conservation (STINASU) and includes 6000 ha of primary montane rain forest surrounding the Brownsberg, a table mountain $500 \mathrm{~m}$ high of the Guiana Shield Formation. This region is seasonal with rainy seasons from May to August and from December to February and with dry seasons from August to November and from February to April (Haverschmidt 1968). The onset and severity of these seasons fluctuate slightly from year to year.

Most of my observations were made along the Irene Val Trail which descends from the Mazaroni Plateau ( $480 \mathrm{~m}$ ) at the north end of the Brownsberg, along a ridge above the Irene Creek. The forest of the study site is typical of a large portion of the park. The understory is relatively open and the canopy height varies between 20 and $35 \mathrm{~m}$ (Fig. 1). Observations were made at display logs on 17 days during 17 October-17 December 1982, for a total of over $50 \mathrm{~h}$, and numerous additional hours were spent in the study area looking for new display sites. Five adult and four immature males were banded at a group of display logs on 3 November 1982. Banding was limited to a single day to minimize the disturbance on the birds at this display site. The birds were quite tame and all the observations were made without a blind. Sound recordings were made during the study by $T$. H. Davis and are on file at the Cornell University Library of Natural Sounds, Ithaca, NY. Sonagrams of the display sounds were made on a Kay Elemetrics Sonagraph 6061-B. The sonagram figures were prepared from tracings of the originals in order to eliminate excess insect and background noise. I inspected specimens of Corapipo in the collections of

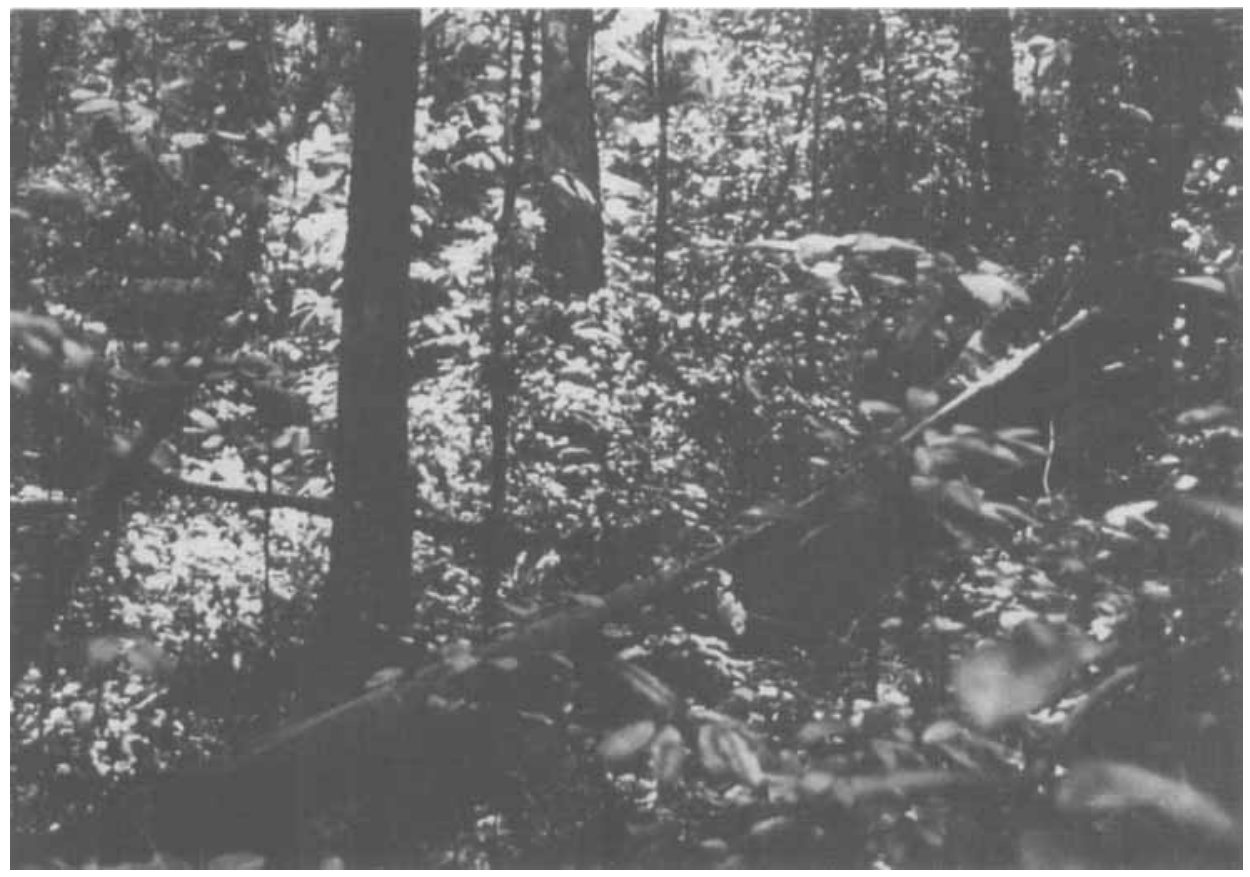

Figure 1. The forest understory in the manakin study area $(350 \mathrm{~m})$ along the Irene Val Trail, Brownsberg Nature Preserve, Suriname. A large Corapipo gutturalis display log can be seen at the centre. 
the Museum of Comparative Zoology, Cambridge, MA, the University of Michigan Museum of Zoology, Ann Arbor, MI, and the American Museum of Natural History, New York, NY, to investigate wing-feather morphology and the production of mechanical display sounds.

\section{Results}

\section{Plumage and foraging behaviour}

C. gutturalis is a small manakin, averaging about $8 \mathrm{~g}$. The adult males are glossy blue-black with a snowy white throat-patch that extends in a V-shape down the chest (Fig. 2). They also have a concealed white wing-patch on the first to seventh primaries which is visible only when the wing is extended. The females are mossy green above and uniform light grey below and lack the distinctive white throat and wing-patches. Juvenile males resemble females before moulting into adult plumage. The moult begins with a black mask around the eyes and then continues patchily throughout the rest of the body. Immature males can sometimes be individually identified by their distinctive transitional plumages.

C. gutturalis is common above $200 \mathrm{~m}$ in the Brownsberg and is most often encountered foraging singly or in pairs in the middle or upper levels of the forest, above $10 \mathrm{~m}$ from the ground. Like most manakins, it takes both fruit and insects in short hovering sally flights. C. gutturalis sometimes forage in the canopy at large fruiting trees with mixed flocks of tanagers, honeycreepers, warblers, sharpbills Oxyruncus and other manakins. Once I observed an immature male foraging at $2-3 \mathrm{~m}$ with a mixed flock of antbirds and furnariids.

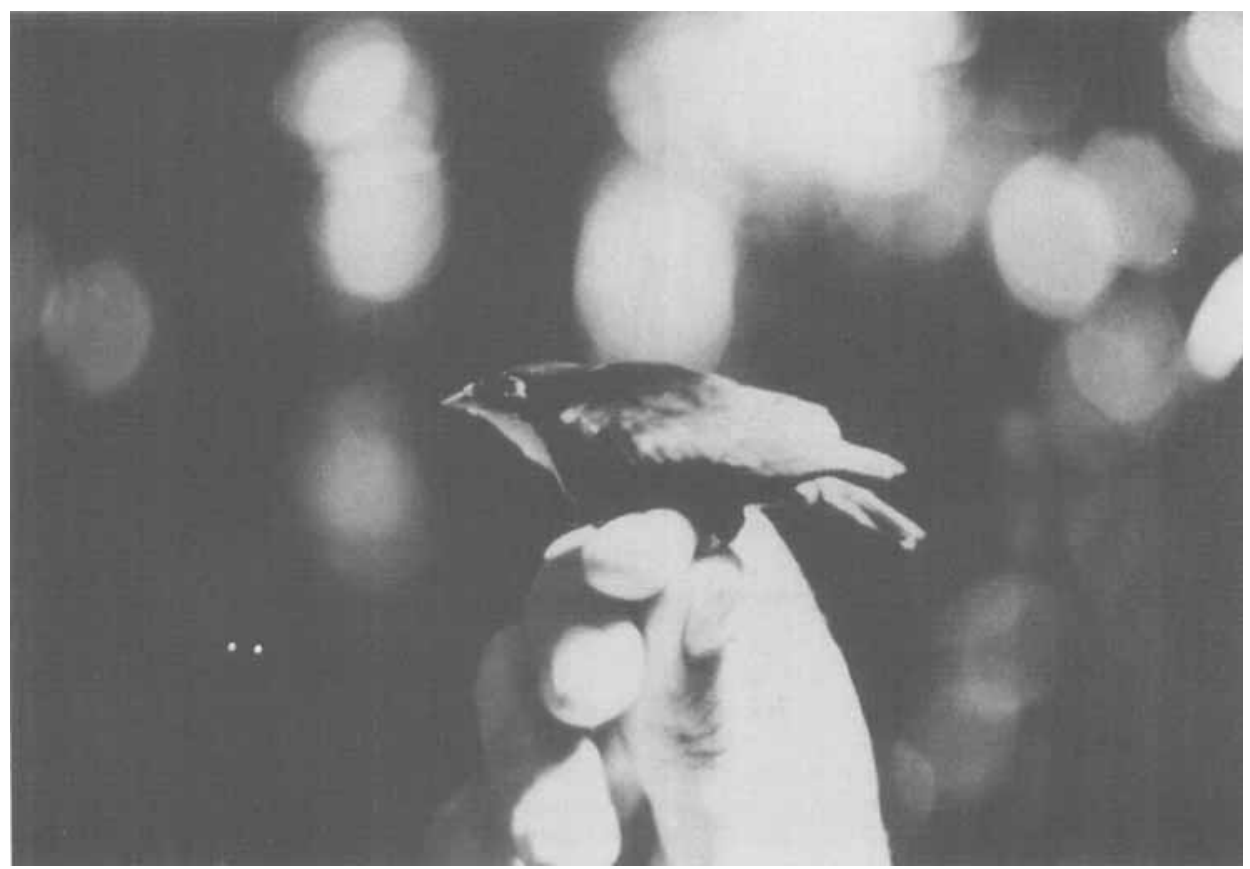

Figure 2. Adult male Corapipo gutturalis. 


\section{Elements of the courtship display}

The courtship performance is composed of a number of diverse elements including preliminary displays from perches in trees, displays given in flight and displays given on fallen logs. The displays may be performed either solitarily or simultaneously by a group of competing males. Wherever possible, I have made an attempt to name the display elements so as to conform to the previous descriptions in the literature.

\section{Advertisement call}

While foraging, both sexes utter high thin seeu or seeu-see calls and a variety of high chip notes. The advertisement call given by males at display areas is a lengthened version of this call in which the second syllable of the call is repeated several times: seeu-see-ee-ee-ee (Fig. 3(a)). The first note of the call begins with a wide band $5-6.5 \mathrm{kHz}$ which is slurred down to a narrow band around $1.5 \mathrm{kHz}$. The slurred portion is shortened in the successive notes and is eliminated in the final notes of the call. The shortened version of the call consists of an identical introductory note followed by a single $5-6.5 \mathrm{kHz}$ note. A bout of courtship display is usually preceded by an increase in advertisement calling.
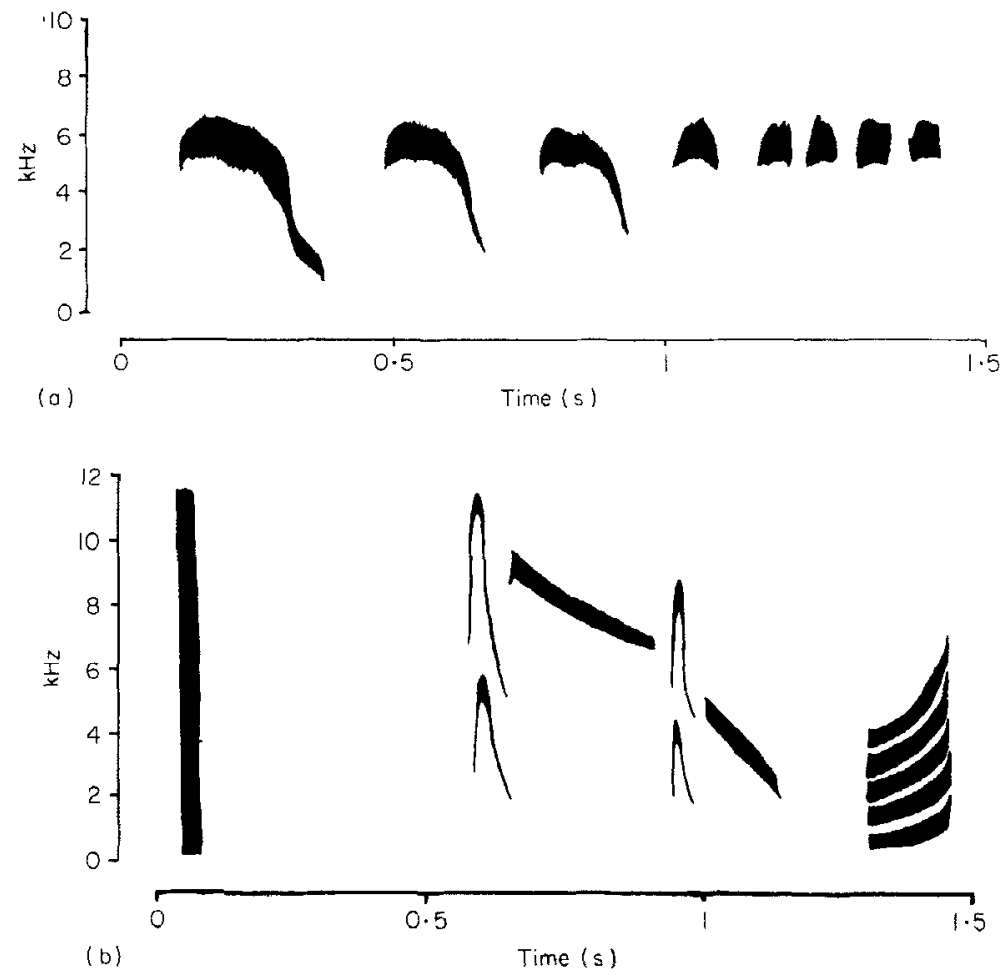

Figure 3. Sonagrams of Corapipo gutturalis vocalizations: (a) advertisement call seeu-see-ee-ee-ee; (b) display call pop-tickee-yeah.

\section{Perch displays}

Males perform a series of displays in trees near logs as preliminaries to log display. A male may display from any perch $1-10 \mathrm{~m}$ high which is clear of obstructing foliage but will usually display at a limited number of favourite perches. All the perch displays are elaborations of the 'bill-pointing' posture in which the male raises his bill vertically, fully exposing his white throat-patch and erecting a small puff of white feathers at the base of the throat patch (Fig. 4(a)). While in bill-pointing posture a male often performs an 


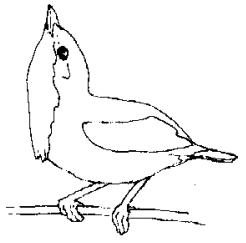

(a)

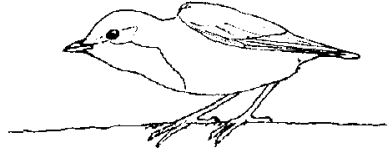

(b)

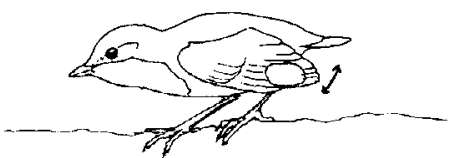

(c)

Figure 4. Elements in the courtship display of Corapipo gutturalis: (a) bill-pointing posture; (b) hunched posture; (c) wing-shiver display.

'about-face' on the perch with a quick $180^{\circ}$ hop. The about-face manoeuvre may be repeated up to five times in succession. In the 'to-and-fro' display a male perched in bill-pointing posture flies rapidly to another perch between 0.5 and $2 \mathrm{~m}$ away and lands, resuming bill-pointing posture. After a pause of a second or two, the male about-faces on the perch, pauses again and returns to his original perch. The flights between perches happen so quickly that a male sometimes appears to maintain the bill-pointing posture in flight. One individual repeated the to-and-fro display 15 times with only brief pauses between each repetition. Occasionally a male proceeds to a third perch by eliminating an about-face in the sequence. Periods of display are sometimes interspersed with advertisement calling, but the displays are performed silently.

\section{Display call}

Male C.gutturalis perform displays in flight while approaching display logs (see description below). At the end of many 'log-approach' displays, males produce a complex vocal and mechanical call and perform aerial manoeuvres as they land on a display $\log$. This 'display call' begins with a series of two to ten high thin seee notes that are given in flight. As the male approaches the $\log$, the volume, intensity and duration of the last two or three notes are increased. When he reaches a point approximately $0.5 \mathrm{~m}$ above the log, the male suddenly stalls in flight with a single flash of his white wing-patches and drops to the log, producing a muffled $p o p$. Immediately after landing on the log, he rebounds up into the air with a flip of his wings and lands $30-40 \mathrm{~cm}$ down the $\mathrm{log}$, facing back where he first landed. During the rebound the male utters a sharp squeaky tickee-yeah. The entire sequence is very rapid, producing a single continuous seee ... seeepop-tickee-yeah call (Fig, 5). A male may omit the rebound so that the last portion of the call is given as he lands on the log.

The sonagram shows the complexity of the display call (Fig. 3(b)). The introductory seee notes (not illustrated) are long drawn-out $5-6.5 \mathrm{kHz}$ bands which closely resemble the advertisement call in frequency. The pop appears as a single wide band across all frequencies. The tickee portion of the call

(b)

(a)

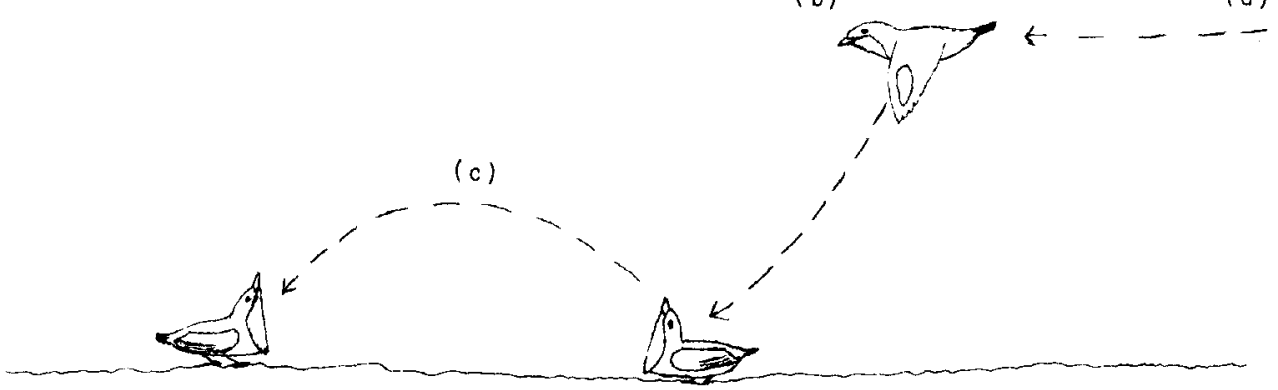

Figure 5. The performance of the display call of Corapipo gutturalis: (a) introductory seee notes are given while in flight towards the log; (b) the male stalls in mid-flight with a snap of the wings, producing the pop note and revealing his white wing-patches, and then drops to the display log; (c) after landing in a billpointing posture, the male rebounds up from the log, turns in flight flashing the white wing-patches again and, giving the tickee-yeah call, lands in a bill-pointing posture facing in the opposite direction. 
consists of two series of abruptly rising and falling harmonic notes followed by a single down slurred band from 10 to $8 \mathrm{kHz}$ and from 6 to $1.5 \mathrm{kHz}$ successively. The final yeah note of the call is composed of five harmonic bands from 1 to $5 \mathrm{kHz}$ which rise to inflection up to 1.5 to $7 \mathrm{kHz}$.

After observing the display call many times, I determined that the pop note was produced mechanically. The pop is produced only in flight and is always accompanied by a sudden stall or change in flight direction and a conspicuous flash of the white wing-patches, which are a blur in normal flight.

\section{Log-approach and flight-song displays}

The displays performed while in flight to the log vary tremendously in length and intensity. In the vast majority of $\log$-approach displays, males fly to the log in normal flight from a perch $1-4 \mathrm{~m}$ high within 10 $m$ of the $\log$. In the most elaborate type of log approach, a male flies nearly vertically out of the trees to a height of 10-25 $\mathrm{m}$ above the canopy, often in bill-pointing posture. As he ascends, the male utters a series of three or more seee notes which are distinguishable from those given during the standard log approach by their more emphatic insect-like character. The seee notes reach a dramatic crescendo at the height of the display when the male suddenly plummets back down into the forest and lands on the display log.

I observed 18 of these flight displays from a clearing on the Irene Val Trail which looked out over the canopy of the forest on the slope below (Fig. 6). Nine of the 18 displays observed ended in a final pop. In two cases a pair of males performed the displays in rapid succession, less than $10 \mathrm{~s}$ apart. I heard the abovethe-canopy seee calls quite regularly while observing at display logs on the forest floor. On four of these occasions I heard the flight-8ong seee calls immediately preceding a display call at an unseen log and twice I saw males land on a log after a series of the more intense seee calls. In the first of these instances, I heard flight-song calls overhead and suddenly saw an adult male drop to the display log. On the second occasion, two banded males were displaying at $a \log$ in a small clearing, where an entire vertical section of the forest

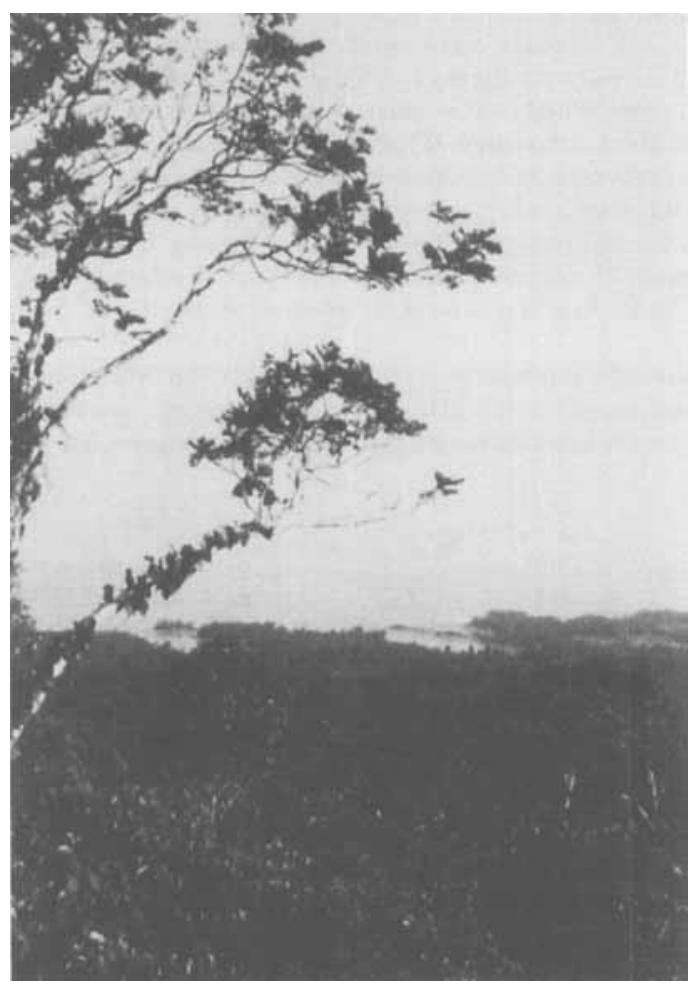

Figure 6. Look-out off the Mazaroni Plateau $(480 \mathrm{~m})$ over the lower slopes of the Brownsberg, Suriname, where some Corapipo gutturalis 'above-the-canopy' flight displays were observed. Lake Affobakka lies in the background. 
was visible. After both birds had been absent for about a minute, I heard the intense seee calls of two birds above the canopy. As the calls reached a crescendo, I saw the same pair of males emerge from the foliage of the canopy $25 \mathrm{~m}$ overhead, plummet in a steep arc down to the log and give the display call as they landed on the $\log$ in quick succession. These observations confirm that the above-the-canopy flights are performed both as elaborate log-approach displays and as independent flight-song displays in which males do not land on a display log.

A male may also perform another entirely different form of log-approach in which he flies from a nearby perch to the $\log$ in a slow undulating 'moth-like' flight, holding his body nearly vertical and fluttering his wings rapidly. The moth-flight $\log$ approach is never followed by the display call and is usually performed by solitary males. Occasionally the same style of flight may be used by a male to fly between display perches.

\section{Fallen log displays}

The culminating displays of the courtship performance are given on a fallen log. Fourteen display logs were located in the study area. All were moss covered and generally free from obstructing vegetation. They varied from 1 to $30 \mathrm{~m}$ in length and from 15 to $100 \mathrm{~cm}$ in diameter and were in various stages of decay (Figs. 1 and 7). Birds usually preferred to display on one particular log segment about $1 \mathrm{~m}$ long.

The fallen log display is composed of repetitions and combinations of several stereotyped postures and manoeuvres. Typically, a male lands on the log, performs some of the display elements and then returns to his perch. A single log display may last for over a minute, but the vast majority last for $1-10 \mathrm{~s}$. With each repetition the display becomes more intense and the sequence becomes more involved. Although males occasionally give fragments of calls from the display $\log$, the displays are performed silently. The log display elements are as follows.

(1) Bill pointing. A male will often begin a log display by landing in bill-pointing posture, facing one end of the log. This posture is identical with that assumed during the perch displays (Fig. 4(a)), except that

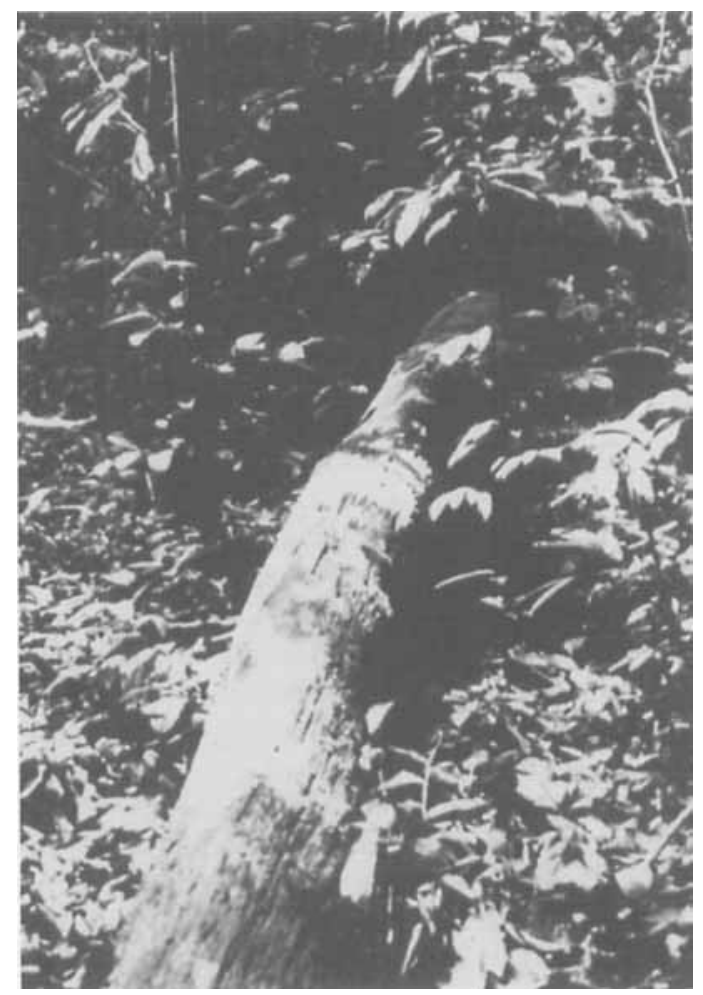

Figure 7. Corapipo gutturalis display log (approximately $30 \mathrm{~cm}$ in diameter). 
the male crouches so that his throat-patch touches the log. Bill pointing is the most common log display posture as it is often performed between other elements of the display. From the bill-pointing posture a male will often make abrupt $90^{\circ}$ or $180^{\circ}$ turns in place. One of the most common log display elements is the to-and-fro display in which a male flies forwards with a quick flip of the wings, turns in mid-air and lands in bill-pointing posture $20-40 \mathrm{~cm}$ down the $\log$, facing in the opposite direction. This display is performed with rapid machine-like precision and is made strikingly conspicuous by the flash of the male's white wing-patches as he turns in flight. The to-and-fro display may be repeated up to ten times with only short pauses in between repetitions. The rebound that is given at the end of many log approaches is identical with a single to-and-fro manoeuvre performed immediately after landing on the log.

(2) Hunched posture. In this display, a male perched on the display log lowers his head and raises the 'wrists' of his closed wings, assuming a distinctly 'hunched' posture (Fig. 4(b)). This posture is usually maintained for only a second or two. It may be performed by a solitary male between other display elements, but it is most commonly given in response to an intruding male. If an intruder lands on the $l o g$, the first male may assume the hunched posture and walk rapidly towards the intruder in an attempt to displace him from the log.

(3) Wing-shiver display. In this display a male lowers its head, as in the hunched posture, and opens the wings, exposing the upper surfaces of the wings and the white wing-patches. At the same time, the male struts backwards around the log rapidly 'shivering' his wings with slight opening and closing movements (Fig. 4(c)). A single burst of display may last for less than a second to several seconds, in which time a male may travel up to $30 \mathrm{~cm}$ in any direction around the $\log$. These movements are performed with the jerky energetic quality of a wind-up toy. The wing-shiver display is the most intense element in the entire repertoire and is only performed during the most excited log display sequences. The wing-shiver display is probably the 'slow undulating crawl' reported by T. A. W. Davis (1949).

\section{Performance of the display}

Courtship display was performed sporadically from just after dawn to the late afternoon. The amount and time of display varied greatly from day to day, with the most active periods occurring from $0800 \mathrm{~h}$ to $1200 \mathrm{~h}$. Periods of display also varied in length. Some individuals continued calling and displaying continuously for over 1.5 $h$, but most often periods of active display lasted for 15-45 minutes.

The arrangement of the various display elements in the performance is varied and any specific element may be emphasized or omitted in a given performance. Typically, display by a solitary male begins with a period of advertisement calling and possibly some perch displays. Eventually, he performs log approaches and log displays. Normally the male drops down from his perch to a lower perch nearer the $\log$ and performs repeated approaches from there. In the first of a series of $\log$ displays a male usually merely perches on the log, looks 'nervously' to each side and then returns to his perch. As he repeats the log approaches, the male gives the full display call more often, and the log displays themselves become more involved, including bill-pointing, to-and-fro and eventually wing-shiver elements. After many log approaches, a male may eliminate the display call and commerce wingshiver display immediately on landing. A period of solitary display may last 45 minutes.

The development of display by groups of males progresses in a similar way but includes aggressive interactions between the males. Groups include up to seven adult and immature males which may either assemble at a display log or arrive there together. The excitement of the group increases as they begin calling and chasing each other around the upper levels of the forest. Elaborate to-and-fro perch displays are most commonly performed by males in groups at this stage of the display. As males drop down from the upper levels of the forest and begin to perform log approaches, they compete for control of the display log. Males performing log displays are often interrupted by intruding males which either swoop down over the $\log$, producing a single pop in flight, or try to land on the log, giving the full display call. Often, more than one male will attempt to land on the log at once, producing a 
confusing flurry of pops and display calls. On large logs, males may display simultaneously on several sections of the log, but their behaviour is neither cooperative nor synchronized in any way. The longest bout of group display which I observed lasted for 70 minutes. More typically, males will display at a log for 5-10 minutes and then proceed to another nearby $\log$. A group of males may display at five or more closely adjacent logs in succession before leaving an area.

Certain banded males were more successful than others at maintaining control of a log during group display. One banded adult male who displayed solitarily at a group of adjacent logs on many occasions over a 6 week period was the most successful at defending display sites during group display at these logs, although he was not completely dominant. Immature males varied in display proficiency from obviously less adept to indistinguishable from the adults, but for the most part immature males were not successful in defending display logs from intruding adults. It appears that a male's ability to defend a display site against intruders is related to his age and possibly his experience in solitary display at that site.

The presence of immature males made it difficult to determine the sex of femaleplumaged birds at the display sites, but I did observe two visits to the display logs by probable females. In both instances, female-plumaged birds were perched on the log in a manner unlike any known male. Once, a presumed female was perched on a log where a group of three adult and two immature males were displaying. This individual was observing an adult male performing the wing-shiver display from 20 $\mathrm{cm}$ away, a much closer distance than any known male was ever allowed to approach. After watching the display intently for about $30 \mathrm{~s}$, the female flew off. In the second instance, a single adult male was engaged in intense wing-shiver display $2040 \mathrm{~cm}$ away from two presumed females. The male performed repeated log-approach displays and began the wing-shiver display immediately on landing on the log, walking backwards towards the two females. A second adult male arrived at the log after several minutes and displaced the first briefly. The display continued for about 5 minutes until all four birds flew off together. I did not observe any copulation attempts, but T. A. W. Davis (1949) observed a pair copulate on a mossy log after display by a group of six or more males and females. From both Davis's account and my own observations, it appears that $C$. gutturalis males use the log display, and particularly the wing-shiver display, as a solicitation to females and that females visit display logs during display by groups of males.

\section{Spatial organization of the display sites}

The 14 display logs located were dispersed along two sections of the Irene Val Trail $250 \mathrm{~m}$ long. They appeared to be organized in two exploded leks about $250 \mathrm{~m}$ in diameter and $350 \mathrm{~m}$ apart. Despite persistent searching, no display logs were found in the vegetatively similar area between the two large display areas. Within each display area, I found logs both in loose groups and in solitary situations at some distance from any other known log. However, the sporadic and transient nature of the display groups made it difficult to be sure of finding all the display sites, and the number of logs found was certainly related to the amount of time spent in an area. At the site where I made most of my observations, I located seven display logs within an area $50 \mathrm{~m}$ in diameter, and several of these were located only after many days of observations. Many of the 'single' logs were probably near other unrecognized display logs, so that the display sites could have been evenly dispersed throughout the two areas. Furthermore, males appear to display opportunistically at logs which are not habitual display sites, and so the distinction between the established sites and 
the occasionally used logs is not clear. There is certainly an excess of suitable logs throughout the area.

It was not possible to determine whether the two separate areas of display logs were used by separate populations of males and therefore constituted independent leks with separate pools of mates, but resightings of the banded males provided some information on male ranging habits. Nine males were banded on 3 November 1982 during group display at the main observation site. Of the five adult males banded, only two were resighted. One was observed displaying on many occasions over a 6 week period at the capture site, and the other was seen there only once. Of the four immature males, two were resighted at the capture site two or three times, and a third was seen once at a log in the other display area over $350 \mathrm{~m}$ away. None of the other birds was resighted. Although these data are far from conclusive they indicate that, of the males which display in a group, some display faithfully at that site for an extended period, while others appear to be quite transient in their patterns.

\section{Discussion}

The courtship display of $C$. gutturalis is similar to that of the other species in the genus, the White-ruffed Manakin Corapipo leucorrhoa which ranges from Honduras to northern Colombia and northwestern Venezuela. Displays of C. leucorrhoa have been described by Aldrich \& Bole (1937), Slud (1964) and T. H. Davis (1982) but were most thoroughly studied by Skutch (1967) in Costa Rica.

$C$. leucorrhoa, like C. gutturalis, displays on mossy logs and performs displays while in flight towards the logs. Skutch (1967) described two types of log-approach display for $C$. leucorrhoa. The first is a slow silent undulating flight from a nearby perch which seems very similar to the moth-flight $\log$ approach of $C$. gutturalis, although it is apparently much more commonly performed. The second is a direct rapid descent from the foliage above the $\log$ that ends in a partly vocal, partly mechanical call which Skutch described as flap chee waaa. This display appears to be nearly identical with the log approach and pop-tickee-yeah call of C.gutturalis both in general form and in method of sound production. Several observers (Davis 1982, Mark Robbins, pers, comm.) have seen $C$. leucorrhoa perform flight-song displays above the canopy in Panama. Presumably, C. leucorrhoa performs these flights as $\log$-approach displays as well. Unlike C. gutturalis, a male $C$. leucorrhoa can erect its entire white throat-patch to form a large ruff, and it extends its ruff during flight and $\log$ displays. While performing the $\log$ display, a male $C$. leucorrhoa merely lowers its head and occasionally flicks its wings (Skutch 1967). Interestingly, C. leucorrhoa lacks white wing-patches and does not perform the elaborate to-and-fro and wingshiver displays in which they are so prominently displayed by $C$. gutturalis. The organization of the display groups of $C$. leucorrhoa and C.gutturalis are also similar. Skutch (1967) described the three $C$. leucorrhoa display logs that he observed as 'belonging to' three or four males each, but he did not elaborate on their spatial distribution.

C. gutturalis appears to produce its wing pop without the wing-feather specializations used by some other manakin species. Inspection of 50 specimens of $C$. gutturalis showed no thickening of the shafts or specializations in the emargination of the wing feathers in either males or females. However, the wide inner webs of the secondaries and the first six primaries do overlap with the surfaces of the adjacent feathers; $C$. gutturalis appears to produce the pop by rapidly snapping this surface of the wing against the air, creating a low pressure area behind the wing. The Central American subspecies of $C$. leucorrhoa $(C$. l. altera and $C$. l. heteroleuca) have a 
different wing morphology in that the seventh to tenth primaries are thinner and distinctly curved in shape (see Ridgway 1907 for illustration). C. l. leucorrhoa from Colombia and Venezuela has, in addition, a greatly reduced tenth primary which forms a short barb at the leading edge of the wing (see Wetmore 1972). Unfortunately, there are no accounts of the displays of $C$. l. leucorrhoa and so it is not known whether it uses this particular feather morphology in the production of a mechanical display sound.

Although the displays of many manakin species have not yet been described, the behaviour of Corapipo is unique among known manakins in several respects. No other manakins are known to display on mossy fallen logs or to perform such elaborate flight displays. These dramatic flights appear to serve as advertisements to attract females foraging in the canopy down to the display logs on the forest floor and may have evolved through selection for this function. The wing-shiver display of $C$. gutturalis is also quite distinct, although it bears some similarities to the 'wingshiver' solicitation displays performed by the Pipra aureola species group (Snow 1963, Schwartz \& Snow 1979, Robbins 1983). Interestingly, all three of these species have white wing-patches that are conspicuously flashed during the display.

Corapipo also differs from other manakins in the organization of its breeding system. Known manakins vary in breeding system organization from classical lek species such as the White-bearded Manakin Manacus manacus (Snow 1962, Lill 1974) and exploded lek species to cooperatively displaying species of the genus Chiroxiphia (Foster 1977, 1981; for a review see Payne 1984). While some male Corapipo display habitually at a few sites in a territorial manner, as many as six additional males may attempt to display on one of these logs at the same time, and 'territorial' males join group display at other sites as well. This amount of inter-male 'disruption' is unknown in other manakin species (Lill 1976, Foster 1981, 1983). It seems clear that these display sites do not constitute display territories in the usual sense. Apparently, Corapipo males compete simultaneously for control of a single display site during group display rather than competing for female visits by displaying in neighbouring exclusive territories, as in a classical lek. The abandonment of exclusive display territories for the competitive group display at a series of sites appears to have resulted in a form of 'detached' or 'mobile' lek.

The evolution of this type of mobile lek system has not been discussed. Bradbury (1981) has proposed that lek size and inter-lek distance are determined by an equilibrium between female choice for more aggregated males and male preference for increased dispersion. Foster (1983) has further hypothesized that disruption of courtship is inversely proportional to the distance between members of the same sex and that female choice for small inter-male distances and large lek sizes should be countered by the increasing costs to females of disruption in highly concentrated leks. C. gutturalis fits Foster's predictions in that disruption is at its highest while males are at the limit of close proximity, physical competition for the same display site. My observations of female visits and Davis's (1949) observation of a copulation indicate that female $C$. gutturalis sometimes choose to visit display sites during group display, when both disruption and efficiency of comparison are at their highest, and so disruption does not appear to be detrimental enough to offset female preference for these aggregations. The breeding system of Corapipo could have evolved through strong female choice for highly aggregated males. Under these conditions, disruption would become so frequent that it would not be feasible for males to maintain exclusive display territories against disrupters. The result would be a system of highly competitive and disruptive group display centred around a series of different sites. Females would benefit by mating with the dominant male during group display because of his success in defending the site through physical encounters with all the other possible mates. 
Although further investigation of $C$. gutturalis is necessary to determine the spatial organization of the display areas and the relationship between the males and the display sites, the courtship behaviour of Corapipo appears to differ markedly from that of all other known manakins and may be an example of another extreme form of breeding system within the family.

I am grateful to A. R. Gahan for financial support for my work in Suriname. I am indebted to STINASU for making my work possible, and especially to Judy and Hank Reichardt for their hospitality and assistance during my stay. Dr B. de Jong, W, van Stockum, S. Mofo and F. van Troon were all a great help in the field. T. H. Davis was kind enough to share his tape recordings and field notes on Corapipo. P. Donaghue drew some of the display figures and also shared his field notes. Dr J. Bull at the American Museum of Natural History allowed me to inspect specimens in his care. Dr R. A. Paynter, Jr, has commented on the manuscript and allowed me to use the Museum of Comparative Zoology collections and bird library. Dr M.S. Foster made numerous helpful comments and improvements on an earlier draft of the paper, and Dr K. Fristrup, R. J. O'Hara, Dr R. B. Payne, A. Pirie and M. Plotkin were all helpful in various stages of the project. To all these people I extend my sincere thanks.

\section{References}

AldRICH, J.W. \& Bole, B.P. 1937. The birds and mammals of the western Azuero Peninsula (Republic of Panama). Sci. Publ. Cleveland Mus. Nat. Hist. 7: 1-198.

Bradbury, J.W. 1981. The evolution of leks. In Alexander, R.D. \& Tinkle, D.W. (eds), Natural selection and social behavior: 138-169. New York: Chiron.

Davis, T.A.W. 1949. Display of the White-throated Manakins Corapipo gutturalis. Ibis 91: 146-147.

Davis, T. H. 1982. A flight-song display of the White-throated Manakin. Wilson Bull. 94: 594-595.

FOSTER, M.S. 1977. Odd couples in manakins: a study of social organization and cooperative breeding in Chiroxiphia linearis. Am. Nat. 111: 845-853.

FoSTER, M.S. 1981. Cooperative behavior and social organization of the Swallow-tailed Manakin (Chiroxiphia pareola). Behav. Ecol. Sociobiol. 9: 167-177.

FosteR, M.S. 1983. Disruption, dispersion, and dominance in lek-breeding birds. Am. Nat. 122: 53-72.

Haverschmidt, F. 1968. The birds of Surinam. London: Oliver \& Boyd.

LiLL, A. 1974. Sexual behavior in the lek-forming White-bearded Manakin (Manacus manacus Hartert). Z. Tierpsychol, 36: 1-36.

LILL, A. 1976. Lek behavior in the Golden-headed Manakin, Pipra erythrocephala in Trinidad (West Indies). Beihefte $Z$. Tierpsychol 18: 1-83.

Meyer de Schauensee, R. 1970. A guide to the birds of South America. Wynnewood, PA: Livingston.

Meyer de Schauensee, R. \& Phelps, W.H. 1978. A guide to the birds of Venezuela. Princeton, NJ: Princeton University Press.

Payne, R.B. 1984. Sexual selection, lek and arena behavior, and sexual size dimorphism in birds. Ornithological Monographs, 33.

Ridgway, R. 1907. The birds of North and Middle America, Part IV. Bull. U.S. Nat. Mus. 50: 1-973.

Robrins, M.B. 1983. The display repertoire of the Band-tailed Manakin (Piprafasciicauda). Wilson Bull. 95: 321-342.

Schwartz, P. \& SNow, D.W. 1979. Displays of the Wire-tailed Manakin. Living Bird 17: 51-78.

Sкитсн, A.F. 1967. The life histories of Central American highland birds. Publ. Nuttal Club No. $7: 1-$ 213.

Sudd, P. 1964. The birds of Costa Rica. Bull. Am. Mus. Nat. Hist. 128: 1-430.

SNow, D.W. 1962. A field study of the Black and White Manakin, Manacus manacus, in Trinidad, West Indies. Zoologica (New York) 47: 183-198.

SNow, D.W. 1963. Display of the Orange-headed Manakin. Condor 65: 44-48.

Wetmore, A. 1972. The birds of the Republic of Panama, Vol. 3. Smithson. Misc. Collect. 150. 